21. Yau S.K., Ortis-Ferrara G., Srivastava J.P. Claster analysis of bread wheat lines grow in diverse rain fed environment // RACHIS. 1989-8, 2, P. 31-35.

Гудова Людмила Александровна, канд. с.- $x$. наук, ведущий научный сотрудник, ФГБНУ РосНИИСК «Россорго». Россия.

410050 г. Саратов, 1-й Институтский пр-д, 4.

Тел.: 89271242886.

Жужукин Валерий Иванович, $\partial-p$ c.- . наук, проф. кафедры «Растениеводство, селекция и генетика», Саратовский государственный аграрный университет им. Н.И. Вавилова. Россия.

410012, г. Саратов, Театральная пл., 1.
Тел.: (8452) 26-27-83.

Зайцев Сергей Александрович, канд. с.-х. наук, ведущиий научный сотрудник, ФГБНУ РосНИИСК «Россорго». Россия,

Волков Дмитрий Петрович, главный научный сотрудник, ФГБНУ РосНИИСК «Россорго». Россия.

Лёвкина Альбина Юрьевна, младший научный сотрудник, ФГБНУ РосНИИСК «Россорго». Россия.

410050 2. Саратов, 1-й Институтский пр-д, 4.

Тел:. 89271242886.

Ключевые слова: кукуруза; урожайность; высота растений; межфазные периоды; число зерен; кластер; евклидово расстояние.

\title{
CLUSTER ANALYSIS OF ECONOMICALLY VALUABLE TRAITS OF MAIZE HYBRIDS IN THE CONDITIONS OF THE SARATOV RIGHT BANK
}

Gudova Lyudmila Aleksandrovna, Candidate of Agricultural Sciences, Leading Researcher, Russian Research Institute for Sorghum and Maize "Rossorgo". Russia.

Zhuzhukin Valeriy Ivanovich, Doctor of Agricultural Sciences, Professor of the chair "Crop production, Selection and Genetics”, Saratov State Agrarian University named after N.I. Vavilov. Russia.

Zaytsev Sergey Aleksandrovich, Candidate of Agricultural Sciences, Leading Researcher, Russian Research Institute for Sorghum and Maize "Rossorgo". Russia.

Volkov Dmitriy Petrovich, Senior Researcher, Russian Research Institute for Sorghum and Maize "Rossorgo". Russia.

Leovkina Albina Yurievna, Junior Researcher, Russian Research Institute for Sorghum and Maize "Rossorgo". Russia.

Keywords: maize; productivity; plant height; interphase periods; number of grains; cluster; Euclidean distance.

The results of a study of 42 maize hybrids of various ecological and geographical origin by a complex of economically valuable traits in the conditions of the Saratov Right Bank are presented. In order to optimize the breeding process, we used cluster analysis, which allows one to group a large array of hybrids into several groups (classes) that differ in a complex of parameters. As a result of clusterization at the 34th step of iteration, maize hybrids are grouped into 8 clusters according to the main economically valuable traits. It was revealed that the composition of the clusters differs by years of research. The same reaction similarity to environmental conditions was revealed in hybrids: Ross 140 SV and RNIISK 1; Ladozhskiy 292 MV and Ladozhskiy 298 MV; Agata and Dokuchaevsky 190; as well as hybrids Bilyar, Mashuk 171 MV, Mashuk 175 MV, and Baikal. The correct distribution of hybrids across clusters is confirmed by analysis of variance (unorganized repetition). It was established that according to all the studied signs, the differences in the clusters are significant.

\section{РЕЗУЛЬТАТЫ ИСПЫТАНИЙ ОРГАНИЧЕСКИХ ПОЧВОУЛУЧШИТЕЛЕЙ ПРИ ВОЗДЕЛЫВАНИИ ОВОЩНЫХ КУЛЬТУР НА ОРОШАЕМЫХ КАШТАНОВЫХ ПОЧВАХ ЗАВОЛЖЬЯ}

\author{
КОРСАКОВ Константин Вячеславович, Саратовский государственный аграрный \\ университет имени Н.И. Вавилова
}

ПРОНЬКО Нина Анатольевна, Саратовский государственный аграрный университет имени Н.И. Вавилова

ГОВРЯков Александр Сергеевич, Научно-производственное объединение «Сила жизни» ПРОНьКО Виктор Васильевич, Научно-производственное объединение «Сила жизни»

В полевых опытах на орошаемых темно-каштановых почвах Саратовского Заволжъя изучалась эффективность двух новых органических почвоулучшителей производства НПО «Сила Жизни». Они отличаются между собою содержанием общего углерода, соединений азота и солей гуминовых и фульвокислот. Объектами исследований были кормовая свекла, морковъ столовая, капуста белокочанная поздняя, лук репчатый. Выявлены особенности формирования урожайности овощных культур при использовании разных почвоулучшителей и установлены их оптимальные дозы. Показано, что применение почвоулучшителей окупается стоимостью дополнительно полученного урожая. Все изучаемые виды удобрительных средств положительно влияли на содержание витаминов А и С.

В структуре почвенного покрова областей и республик Поволжья преобладают почвы с невысоким естественным плодородием [14]. В первую очередь это относится к типу каштановых почв. Они обладают неудовлетворитель- ными агрофизическими свойствами (высокая плотность, низкие влагоемкость и влагопроницаемость), незначительными запасами гумуса и соединений азота и фосфора, доступных для растений [4]. 
Для улучшения малоплодородных почв, как известно, предлагается широкое использование органических удобрений [9]. Ранее в Поволжье среди них доминирующее положение занимал навоз крупного рогатого скота. Однако после проведения экономических реформ и ликвидации общественного поголовья имеется возможность внести на 1 га пашни не более 30 кг навоза. Требуется же его не менее 5 т на 1 га пашни.При этом надо учесть, что более половины его массы приходится на воду. Это делает экономически невозможным транспортировку навоза на большие расстояния.

Второй источник пополнения запасов органического вещества почвы - солома зерновых культур. Она содержит 38-42 \% органического углерода, который составляет основу почвенного гумуса. С одной тонны соломы в почву поступает около 400 кг/га углерода. Однако надо помнить, что солому можно применять только на полях, где возделываются зерновые культуры. Сбор, перевозка, разбрасывание и заделка соломы на другие поля экономически нецелесообразна. При этом солома ячменя, овса, проса, риса, гречихи является ценным грубым кормом для крупного рогатого скота. Она вывозится с полей и на удобрительные цели не используется. При разложении соломы в почве интенсивно размножаются целлюлозоразрушающие микроорганизмы [7]. Онирезкоухудшаютазотный режимпочвы и это требует добавлять к каждой тонне соломы по 10 кг/га (в д.в.) азотных удобрений [8].

Очень эффективно применение зеленого удобрения (сидератов). Однако сидеральные культуры невозможно возделывать в регионах с резко выраженным дефицитом летних осадков (в том числе и в зоне каштановых почв). Кроме того, для получения зеленого удобрения необходимо отчуждение определенной части пашни.

Исходя из перечисленных выше аргументов, становится понятным, что для очень многих групп сельскохозяйственных культур (плодовые, ягодные, овощные, технические, декоративные) применение органических удобрений становится проблематичным. Отсюда возникает необходимость поиска новых источников органических соединений для обогащения почв. После обобщения и критического анализа зарубежного опыта производства почвоулучшающих препаратов в НПО «Сила Жизни» разработана и прошла производственную проверку технология получения почвоулучшителей на основе переработки природного минерала леонардита. Их испытания в вегетационных и мелкоделяночных опытах показали положительные результаты $[6,10,12]$.

Цель настоящей работы - изучить влияние новых почвоулучшителей производства НПО «Сила жизни» на урожайность овощных культур, возделываемых на орошаемых каштановых почвах Саратовского Заволжья.

Методика исследований. Полевые опыты проводили в 2016-2018 гг. в К(Ф)Х «Семья Жайлауловых» (с. Терновка Энгельсского р-на Саратовской области). Объекты исследований: кормовая свекла Эккендорфская желтая, морковь столовая Шантене, капуста белокочанная поздняя Агрессор, лук репчатый Халцедон. В опытах применяли два вида органоминеральных удобрений, зарегистрированных под марками Реасил сойл кондиционер для органического земледелия (далее в тексте статьи - улучшитель) и Реасил сойл кондиционер для восстановления плодородия почв (далее в тексте - восстановитель). Свидетельство о государственной регистрации агрохимикатов №1836 выдано Министерством сельского хозяйства Российской Федерации 22.03.2018 г.

Визуально оба препарата представляют гранулы черного цвета (размер - как у аммиачной селитры). Содержание общего органического вещества (в перерасчете на сухую массу) у них составляет 80-85\%. Отличия между ними заключаются в следующем. Улучшитель содержит 95-96 \% природных гуминовых кислот и 45 \% фульвокислот от общей органической массы. Восстановитель имеет 54-56 \% природных гуминовых кислот, 4 \% фульвокислот и около 40 \% калиевые солей гуминовых кислот от общей органической массы. Следовательно, в почве восстановитель является более активным химическим компонентом.

В наших опытах с корнеплодами (табл. 1) оба почвоулучшителя вносились в разных дозах под предпосевную обработку почвы. При возделывании капусты белокочанной (табл. 2) и лука репчатого (табл. 3) после внесения почвоулучшителей вегетирующие растения опрыскивали водным раствором препаратов на основе гуминовых кислот. Первую обработку производили гуматом калия-натрия с микроэлементами (1,0 л/га) две последующие - реасилом форте азот гумик по 2,0 л/га каждая. Эти препараты показали высокую эффективность в ранее проведенных исследованиях с овощными культурами $[1-3,11,13,15]$.

Закладка полевых опытов, а также дисперсионный анализ результатов учета урожаев производились по Б.А. Доспехову [5]. Содержание витамина А (каротин) в корнеплодах определялось по Сапожникову после экстрагирования бензином, витамина С (аскорбиновая кислота) в плодах капусты и лука - по Мурри после экстрагирования смесью соляной и метафосфорной кислот [16].

Учетная площадь делянок колебалась от 22,6 м² (лук репчатый) до 27,6 м² (свекла кормо- 
вая). Повторность вариантов - четырехкратная. Расположение делянок - двухрядное. Уборка урожая на опытах осуществлялась вручную. Полив корнеплодов производили установкой мелкодисперсного дождевания Райн Стар E-41, капусты и лука - через систему капельного орошения внутрипочвенно.

Почва опытного участка - темно-каштановая террасовая левого берега Волги;по гранулометрическому составу среднесуглинистая, среднемощная, среднегумусная, не солонцеватая. Для овощных культур ее обеспеченность легкогидролизуемым азотом по Тюрину-Кононовой низкая (30-40 мг/кг), доступным фосфором по Мачигину низкая (31-45 мг/кг), обменным калием - повышенная и высокая (290-350 мг/кг).
Результаты исследований. В опыте с кормовой свеклой Эккендорфская желтая (табл. 1) было отмечено повышение урожайности корнеплодов с увеличением дозы почвоулучшителей. Но происходило это не в пропорциональной зависимости. Так, увеличение дозы улучшителя в четыре раза (варианты 2 и 4) повысило прибавку урожая в среднем за три года на 7,4 т/га (прирост $8 \%$ к варианту 2). Шестикратное увеличение массы восстановителя (варианты 5 и 7) обеспечило дополнительный прирост массы корнеплодов на 20,1 т/га. В итоге на варианте 7, где в почву внесли 900 кг/га восстановителя, получили самую высокую в условиях экспериментов урожайность корнеплодов кормовой свеклы.

Морковь столовая Шантене также положительно отзывалась на внесение почвоулуч-

Таблица 1

Влияние органических почвоулучшителей на урожайность корнеплодов, т/га

\begin{tabular}{|c|c|c|c|c|c|c|c|c|}
\hline \multirow{2}{*}{ Вариант } & \multicolumn{4}{|c|}{ Год } & \multicolumn{2}{|c|}{ Прибавка } & \multirow{2}{*}{$\begin{array}{c}\text { Кондиция, } \\
\text { \% }\end{array}$} & \multirow{2}{*}{$\begin{array}{c}\text { Витамин A, } \\
\text { мг-\% }\end{array}$} \\
\hline & 2016 & 2017 & 2018 & среднее & $\mathrm{T}$ & $\%$ & & \\
\hline & \multicolumn{8}{|c|}{ Кормовая свекла Эккендорфская желтая } \\
\hline 1. Контроль & 103,3 & 95,6 & 81,4 & 93,4 & - & 100 & 100 & 10,9 \\
\hline 2. Улучшитель 250 кг/га & 111,6 & 102,8 & 90,4 & 101,6 & 8,2 & 109 & 100 & 11,6 \\
\hline 3. Улучшитель 500 кг/га & 112,6 & 103,5 & 91,2 & 102,4 & 9,0 & 110 & 100 & 11,8 \\
\hline 4. Улучшитель 1000 кг/га & 118,8 & 112,1 & 96,0 & 109,0 & 15,6 & 117 & 100 & 11,7 \\
\hline $\begin{array}{l}\text { 5. Восстановитель } \\
150 \text { кг/га }\end{array}$ & 108,5 & 98,1 & 87,9 & 98,2 & 4,8 & 105 & 100 & 1,6 \\
\hline $\begin{array}{l}\text { 6. Восстановитель } \\
300 \text { кг/га }\end{array}$ & 124,7 & 103,6 & 107,7 & 112,0 & 18,6 & 120 & 100 & 11,8 \\
\hline $\begin{array}{l}\text { 7. Восстановитель } \\
900 \text { кг/га }\end{array}$ & 120,9 & 129,6 & 104,4 & 118,3 & 24,9 & 127 & 100 & 11,7 \\
\hline \multirow[t]{2}{*}{$\mathrm{HCP}_{05}, \mathrm{~T}$} & 4,20 & 3,62 & 4,06 & & & & & \\
\hline & \multicolumn{8}{|c|}{ Морковь столовая Шантене } \\
\hline 1. Контроль & 34,3 & 56,3 & 39,4 & 43,3 & - & 100 & 92 & 19,2 \\
\hline 2. Улучшитель 250 кг/га & 41,8 & 64,8 & 44,4 & 50,3 & 7,0 & 116 & 93 & 19,4 \\
\hline 3. Улучшитель 500 кг/га & 43,5 & 66,5 & 47,7 & 52,6 & 9,3 & 121 & 94 & 19,6 \\
\hline 4. Улучшитель 1000 кг/га & 48,6 & 75,0 & 49,2 & 57,6 & 14,3 & 133 & 95 & 19,6 \\
\hline $\begin{array}{l}\text { 5. Восстановитель } \\
150 \text { кг/га }\end{array}$ & 40,5 & 61,6 & 43,6 & 48,6 & 5,3 & 112 & 96 & 19,8 \\
\hline $\begin{array}{l}\text { 6. Восстановитель } \\
300 \text { кг/га }\end{array}$ & 48,6 & 65,8 & 47,1 & 53,8 & 10,5 & 124 & 95 & 19,7 \\
\hline $\begin{array}{l}\text { 7. Восстановитель } \\
900 \text { кг/га }\end{array}$ & 49,5 & 73,2 & 47,4 & 56,7 & 13,4 & 131 & 96 & 19,6 \\
\hline $\mathrm{HCP}_{05}, \mathrm{~T}$ & 2,96 & 3,53 & 3,04 & & & & & \\
\hline
\end{tabular}


шителей. Как следует из приведенных данных (табл. 1), все изучаемые варианты обеспечили достоверные прибавки к контролю. Максимальный прирост урожайности в среднем за три года отмечен при внесении улучшителя в дозе 1000 кг/га (вариант 4). Близкие к нему результаты (на 0,9 т/га меньше) показал вариант 7 (восстановитель 900 кг/га). Повышение урожайности этой культуры происходило за счет увеличения средней массы корнеплода и лучшей их сохранности к уборке. Немаловажное обстоятельство имело также положительное влияние почвоулучшителей на снижение доли некондиционной продукции. В соответствии с действующими ГОСТами к таковой относили мелкие корнеплоды, а также поврежденные вредителями и болезнями. В среднем за три года некондиции набиралось от 3,5 т/га (контроль) до 2,6 т/га (вариант 7).

В опыте с капустой белокочанной поздней изучались не только виды почвоулучшителей, но и возможность их сочетания с жидкими удобрениями на основе гуминовых кислот (табл. 2). Установлено, что в среднем за три года увеличение дозы улучшителя в два раза (варианты 2 и 4) позволило дополнительно собрать 6,41 т/га стандартных кочанов капусты. Утроение вносимого в почву восстановителя (варианты 6 и 8) повысило среднюю за годы исследований прибавку на 17,4 т/га. Следует также отметить, что на капусте белокочанной лучше проявилось действие восстановителя плодородия почв.

Таблица 2

Влияние органических почвоулучшителей и препаратов на основе гуминовых кислот на урожайность капусты белокочанной гибрид Агрессор, т/га

\begin{tabular}{|c|c|c|c|c|c|c|c|}
\hline \multirow{2}{*}{ Вариант } & \multicolumn{4}{|c|}{ Год } & \multicolumn{2}{|c|}{ Прибавка } & \multirow{2}{*}{$\begin{array}{c}\text { Витамин C, } \\
\text { мг\% }\end{array}$} \\
\hline & 2016 & 2017 & 2018 & среднее & $\mathrm{T}$ & $\%$ & \\
\hline 1. Контроль & 69,40 & 78,00 & 72,47 & 73,29 & - & 100 & 24,8 \\
\hline 2. Улучшитель 500 кг/га & 79,33 & 83,84 & 89,24 & 84,16 & 10,87 & 115 & 25,8 \\
\hline $\begin{array}{l}\text { 3. Улучшитель } 500 \text { кг/га + } \\
\text { + гумат K/Na 1,0 л/га } \\
\text { + гумик N 4,0 л/га }\end{array}$ & 104,72 & 94,78 & 92,53 & 97,35 & 24,06 & 133 & 25,6 \\
\hline 4. Улучшитель 1000 кг/га & 90,86 & 86,41 & 94,44 & 90,57 & 17,28 & 124 & 25,9 \\
\hline $\begin{array}{l}\text { 5. Улучшитель } 1000 \text { кг/га + } \\
\text { + гумат K/Na 1,0 л/га } \\
\text { + гумик N 4,0 л/га }\end{array}$ & 99,31 & 90,35 & 96,43 & 95,37 & 22,08 & 131 & 25,9 \\
\hline 6. Восстановитель 300 кг/га & 91,08 & 86,92 & 96,64 & 91,55 & 18,26 & 125 & 25,4 \\
\hline $\begin{array}{l}\text { 7. Восстановитель } 300 \text { кг/га + } \\
\text { + гумат K/Na 1,0 л/га } \\
\text { + гумик N 4,0 л/га }\end{array}$ & 92,39 & 99,88 & 104,50 & 98,93 & 25,64 & 135 & 25,6 \\
\hline 8. Восстановитель 900 кг/га & 99,30 & 110,54 & 115,46 & 108,43 & 35,14 & 148 & 25,8 \\
\hline $\begin{array}{l}\text { 9. Восстановитель } 900 \text { кг/га + } \\
+ \text { гумат K/Na 1,0 л/га } \\
+ \text { гумик N 4,0 л/га } \\
\mathrm{HCP}_{05}, \mathrm{~T}\end{array}$ & 118,41 & 106,66 & 109,21 & 111,43 & 38,14 & 152 & 25,9 \\
\hline
\end{tabular}


Росту урожайности капусты белокочанной способствовали опрыскивания вегетирующих растений водными растворами удобрений на основе гуминовых кислот. Троекратное их применение повысило урожайность стандартной продукции на 13,19 т/га (варианты 2 и 3) - на 7,38 т/га (варианты 6 и 7). Можно отметить еще одно выявленное обстоятельство: там, где вносили высокие дозы почвоулучшителей, действие гуминовых удобрений заметно снижалось. В целом же максимальную продуктивность капусты белокочанной получили при сочетании 900 кг/га восстановителя и трех- кратной обработки посевов гуминовыми удобрениями (вариант 9).

При возделывании лука репчатого (табл. 3) были выявлены практически те же закономерности, что и на других овощных культурах: оба изучаемых почвоулучшителей положительно влияли на урожайность, которая повышалась с увеличением дозы их внесения.Отличительной особенностью явилось то, что в опыте с луком репчатым близкие дозы улучшителя и восстановителя (варианты 5 и 9; варианты 4 и 8) показали практически одинаковые результаты. Как и в опыте с капустой белокочанной, сочетание

\section{Влияние органических почвоулучшителей и препаратов на основе гуминовых кислот на урожайность лука репчатого гибрид Халцедон, т/га}

\begin{tabular}{|c|c|c|c|c|c|c|c|}
\hline \multirow{2}{*}{ Вариант } & \multicolumn{4}{|c|}{ Год } & \multicolumn{2}{|c|}{ Прибавка } & \multirow{2}{*}{$\begin{array}{c}\text { Витамин C, } \\
\text { мг\% }\end{array}$} \\
\hline & 2016 & 2017 & 2018 & сренее & т/га & $\%$ & \\
\hline 1. Контроль & 84,72 & 75,87 & 81,18 & 80,59 & - & 100 & 5,1 \\
\hline 2. Улучшитель 500 кг/га & 88,84 & 90,15 & 86,54 & 88,51 & 7,92 & 110 & 5,3 \\
\hline $\begin{array}{l}\text { 3. Улучшитель } 500 \text { кг/га + } \\
\text { +гумат K/Na 1,0 л/га + } \\
\text { +гумик N 4,0 л/га }\end{array}$ & 94,23 & 98,72 & 90,63 & 94,53 & 13,94 & 118 & 5,5 \\
\hline 4. Улучшитель 1000 кг/га & 90,81 & 92,18 & 98,62 & 93,87 & 13,28 & 117 & 5,5 \\
\hline $\begin{array}{l}\text { 5. Улучшитель } 1000 \text { кг/га + } \\
\text { +гумат K/Na 1,0 л/га + } \\
\text { +гумик N 4,0 л/га }\end{array}$ & 99,14 & 106,84 & 102,32 & 102,77 & 22,18 & 128 & 5,6 \\
\hline 6. Восстановитель 300 кг/га & 89,58 & 94,45 & 92,22 & 92,09 & 11,50 & 115 & 5,5 \\
\hline $\begin{array}{l}\text { 7. Восстановитель } 300 \text { кг/га + } \\
\text { + гумат K/Na } 1,0 \text { л/га + } \\
\text { + гумик N } 4,0 \text { л/га }\end{array}$ & 91,64 & 99,49 & 98,89 & 96,68 & 16,09 & 120 & 5,6 \\
\hline 8. Восстановитель 900 кг/га & 88,81 & 96,64 & 94,18 & 93,21 & 12,62 & 116 & 5,6 \\
\hline $\begin{array}{l}\text { 9. Восстановитель } 900 \text { кг/га + } \\
\text { + гумат K/Na 1,0 л/га + } \\
+ \text { гумик N 4,0 л/га } \\
\mathrm{HCP}_{05}, \mathrm{~T}\end{array}$ & $\begin{array}{r}99,63 \\
5,52\end{array}$ & $\begin{array}{c}106,42 \\
4,64\end{array}$ & $\begin{array}{c}105,50 \\
6,22\end{array}$ & 103,85 & 23,26 & 129 & 5,6 \\
\hline
\end{tabular}


почвоулучшителей и удобрений на основе гуминовых кислот способствовало росту урожайности луковиц за счет увеличения средней массы одного плода, их числа на единице площади и снижения доли некондиционной продукции.

По завершении полевых опытов авторы сделали попытку ответить на очень важный в практическом отношении вопрос - какие изучаемые культуры лучше отзывались на внесение почвоулучшителей? Дать ответ на основе весовых величин урожайности и прибавок к контролю не представляется возможным. Все изучаемые культуры относятся к различным биологическим группам. Поэтому критерием послужили относительные (\% к контролю) показатели продуктивности. Сравнение показало, что кормовая свекла Эккендорфская желтая лучше всего отзывалась на заделку в почву восстановителя (табл. 1, вариант 7). Морковь столовая Шантене показала практически одинаковые результаты при внесении 1000 кг/га улучшителя (вариант 4) и 900 кг/га восстановителя (вариант 7). На капусте белокочанной поздней неоспоримое преимущество показал восстановитель 900 кг/га (табл. 2, варианты 8 и 9). Для лука репчатого одинаково эффективными оказались улучшитель 1000 кг/га и восстановитель 900 кг/га в сочетании с гуминовыми удобрениями (табл. 3, варианты 5 и 9).

При определении агроэкономической эффективности предлагаемых препаратов необходим анализ затрат на их применение. В ценах 2019 г. стоимость 1 т Реасила сойл кондиционер для органического земледелия (улучшитель) составляла 85000 руб., а Реасила сойл кондиционер для восстановления плодородия почв (восстановитель) 110000 руб. По оптовым ценам 2019 г., по которым сельхозтоваропроизводители отпускали в этом году свою продукцию, сложилась следующая картина: свекла кормовая - 5 тыс. руб., морковь столовая - 7 тыс. руб., капуста поздняя - 8 тыс. руб. и лук репчатый - 7 тыс. руб. за 1 т.

После несложных арифметических расчетов можно увидеть, что даже самые высокие в условиях наших экспериментов дозы почвоулучшителей окупаются стоимостью дополнительно полученной прибавки урожая. Максимальный доход от применения восстановителя 900 кг/га отмечали при возделывании капусты белокочанной поздней. При этом необходимо учитывать тот факт, что в опытах с луком и капустой на фоне почвоулучшителей вносились растворы гуминовых удобрений. Они не только достоверно повысили продуктивность этих культур, но и положительно сказались на окупаемости затрат.

Программой исследований предусматри- валось изучение качества урожая овощных культур. В корнеплодах свеклы кормовой и моркови столовой определяли содержание витамина А (каротин), а в плодах лука и капусты витамина С (табл. 1-3). Было установлено, что во все годы проведения полевых опытов оба почвоулучшителя и гуминовые удобрения оказывали положительное влияние на синтез витаминов. В плодах удобренных растений их было в среднем на 9-10 \% больше, чем на контроле.

Заключение. На орошаемых темно-каштановых почвах Саратовского Заволжья установлена высокая отзывчивость на органические почвоулучшители производства НПО «Сила жизни». При этом свекла кормовая Эккендорфская желтая лучше отзывалась на заделку в почву Реасила сойл кондиционер для восстановления плодородия почв в дозе 900 кг/га. Капуста белокочанная поздняя максимальную прибавку урожая показала также при использовании этого препарата. Морковь столовая Шантене и лук репчатый Халцедон одинаково отзывались как на Реасил сойл кондиционер для восстановления плодородия почв, так и на Реасил сойл кондиционер для органического земледелия. Несмотря на высокую стоимость обоих почвоулучшителей, затраты на их применение окупаются доходом от дополнительно полученной прибавки урожая. На примере капусты белокочанной и лука репчатого показано, что существенно повысить эффективность почвоулучшителей можно при сочетании их с удобрениями на основе гуминовых кислот. Все изучаемые средства оказали положительное влияние на содержание витаминов А и С в плодах овощных культур.

\section{СПИСОК ЛИТЕРАТУРЫ}

1. Влияние гуминовых препаратов и хелатных форм удобрений на продуктивность столовой моркови в Саратовском Заволжье при орошении / К.В. Корсаков [и др.] // Аграрный научный журнал. - 2019. - № 4. - С. 16-20.

2. Влияние препаратов на основе гуминовых кислот на продуктивность капусты белокочанной в Саратовском Заволжье при орошении / В.В. Пронько [и др.] // Аграрный научный журнал. - 2018. № 11. - С. 21-24.

3. Влияние гуминовых препаратов на урожайность лука репчатого и его качество на орошаемых каштановых почвах Саратовского Заволжья / Н.А. Пронько [и др.] // Аграрный научный журнал. - 2018. № 10. - С. 31-34.

4. Гришин П.Н, Пронько В.В.Состояние и пути регулирования плодородия черноземных и каштановых почв Саратовской области // Аграрный научный журнал. - 2005. - № 3. - С. 28-31.

5. Доспехов Б.А. Методика полевого опыта. М.: Агропромиздат, 1985. - 416 с. 
6. Корсаков К.В., Пронько В.В. Эффективность почвенных кондиционеров в условиях вегетационных опытов // Агрохимикаты в 21 веке: теория и практика применения: материалы Междунар. науч. конф. Нижний Новгород, 2017. - С. 42-44.

7. Микроорганизмы и плодородие почв: учеб. пособие/ В.В. Пронько [и др.]. - Саратов: Изд-во Саратовского ГАУ, 2005. - 152 с.

8. Минеев В.Г. Агрохимия: учебник. - 2-е изд., перераб. и доп. - М.: Изд-во Моск. ун-та, 2004. - 720 с.

9. Научные основы, состояние и рекомендации применения удобрений в Поволжском регионе / В.Г. Сычев [и др.] // Бюлл. Географ. сети опытов с удобрениями. Вып. 13 - М.: ВНИИА, 2012. - 62 с.

10. Оценка воздействия почвенных кондиционеров в мелкоделяночных экспериментах на искусственных почвенных грунтах / К.В. Корсаков [и др.] // Актуальные проблемы почвоведения, экологии и земледелия: материалы Междунар. научн. конф. - Курск, 2017. - C. 162-166.

11. Пронько В.В., Пронько Н.А., Степанченко Д.А. Влияние гуминовых препаратов на продуктивностьогурца на орошаемых каштановых почвах Саратовского Заволжья // Аграрный научный журнал. - 2018.№ 2. - C. 31-35.

12. Пронько В.В., Корсаков К.В., Васильев Д.Е. Испытания почвенных кондиционеров при выращивании саженцев плодовых и декоративных культур в условиях защищенного грунта // Агрохимикаты в 21 веке: теория и практика применения: материалы Междунар. научн. конф. - Нижний Новгород, 2017. - С. 105-108.

13. Пронько Н.А., Степанченко Д.А., Пронько В.В. Влияние гуминовых препаратов на продуктивность томата на орошаемых каштановых почвах Саратовского Заволжья // Аграрный научный журнал. 2017. - № 9. - С. 24-27.
14. Сычев В.Г., Ефремов В.Н., Лунев М.И. Агрохимическая характеристика почв сельскохозяйственных угодий Российской Федерации. Реестр плодородия почв. - М.: ВНИИА, 2013. - 208 с.

15. Продуктивность свеклы столовой при внесении гуминовых препаратов и хелатных удобрений на орошаемых каштановых почвах Саратовского Заволжья / К.В. Корсаков [и др.] // Аграрный научный журнал. - 2019. - № 5. - С. 25-29.

16. Практикум по агрохимии / под ред. В.Г. Минеева: 2-е изд., перераб. и доп. - М.: Изд-во Моск. ун-та, 2001. -689 c.

Корсаков Константин Вячеславович, канд. с.-х. наук, доцент кафедры «Кормление, зоогигиена и аквакультура», Саратовский государственный аграрный университет имени Н.И. Вавилова. Россия.

Пронько Нина Анатольевна, $\partial-p$ c.- $x$. наук, проф. кафедры «Инженерные изыскания, природообустройство и водопользование»», Саратовский государственный аграрный университет имени Н.И. Вавилова. Россия.

410012, г. Саратов, Театральная пл., 1.

Тел.: (8452) 23-27-83.

Говряков Александр Сергеевич, канд. с.-х. наук, главный спещиалист, научно-производственное объединение «Сила жизни». Россия.

Пронько Виктор Васильевич, $\partial-p$ c.- $x$. наук, проф., зав. отделом науки и развития, научно-производственное объединение «Сила жизни». Россия.

410005, г. Саратов, ул. Большая Садовая, 239.

Тел.: (8452) 44-40-40.

Ключевые слова: темно-каштановые почвы; орошение; почвоулучшители; гуминовые удобрения; свекла кормовая; морковь столовая; капуста белокочанная; лук репчатый.

\section{TRIAL RESULTS OF ORGANIC SOIL CONDITIONERS IN CULTIVATION OF VEGETABLE CROPS ON IRRIGATED CHESTNUT SOILS OF ZAVOLZHYE}

Korsakov Konstantin Vyacheslavovich, Candidate of Agricultural Sciences, Associate Professor of the chair "Feeding, Veterinary Hygiene and Aquaculture", Saratov State Agrarian University named after N.I. Vavilov. Russia.

Pronko Nina Anatolyevna, Doctor of Agricultural Sciences, Professor of the chair "Engineering Surveys, Environmental Engineering and Water Use", Saratov State Agrarian University named after N.I. Vavilov. Russia.

Govryakov Alexander Sergeevich, Candidate of Agricultural Sciences, Chief Specialist, Life Force Research and Production Enterprise. Russia.

Pronko Victor Vasilievich, Doctor of Agricultural Sciences, Professor, Life Force Research and Production Enterprise. Russia.

Keywords: dark chestnut soils; irrigation; soil conditioners; $h u$ mic fertilizers; 3fodder beets; garden carrot; white cabbages; onions.
The effect of two new organic soil conditioners produced by Life Force Research \& Production Enterprise was studied within the field trials on irrigated dark chestnut soils of the Saratov Zavolzhye region. These two products differ in the content of total carbon, nitrogen compounds and salts of humic and fulvic acids. The objects of research were fodder beets, garden carrots, white cabbage of late ripening variety, onions. The features of the yield formation of vegetable crops using different soil conditioners have been identified and their optimal doses have been established. It was shown that the use of soil conditioners was not covered by the cost of additionally gained crop. All types of the studied fertilizers positively influenced the content of vitamins $A$ and $C$. 